\title{
HIV INFECTION AND ACUTE GLOMERULONEPHRITIS
}

Silvia M. O. Titan ${ }^{1}$, Leonardo Testagrossa ${ }^{2}$, Luiz Balthazar Saldanha ${ }^{2}$, Rui Toledo Barros ${ }^{3}$, Viktória Woronik ${ }^{1}$

\section{INTRODUCTION}

Human immunodeficiency virus (HIV) infection is known to be associated with various types of glomerulonephritis. Human immunodeficiency HIV - associated kidney diseases have been classified into 3 different groups: HIVassociated nephropathy (HIVAN), also known as HIV-associated focal and segmental glomerulosclerosis (HIV-FSGS), hemolytic-uremic syndrome (HIV-HUS), and HIV-associated immune complex renal diseases. ${ }^{1,2}$ Previously thought to be rare, these forms of glomerulonephritis have become more frequent, and it is important that the medical community learns more about its diagnosis and treatment.

\section{Case description}

A Caucasian 34-year-old man was referred to our clinic due to an acute loss of kidney function. A diagnosis of HIV infection was made 3 years before the patient had been under regular follow-up at the Infectious Desease Department since then. The last CD4 count (3 months before consultation) was 374 cells $/ \mu \mathrm{L}$, and the HIV viral load was 1350 000 copies $/ \mathrm{mL}(6.1 \mathrm{log})$. He was not on anti-retroviral therapy and had never presented any opportunistic infection. There was no history of diabetes, hypertension, kidney disease, or any other remarkable comorbidity. There was also no history of intravenous drug use or exposure to any nephrotoxic drugs.

Four to five weeks before consultation, he started to have asthenia. He reported no other symptoms, except for foamy urine. One week before consultation, he presented fever and dry cough, with a normal chest X-ray, and was started on azitromycin $500 \mathrm{mg} /$ day and prophylaxis with sulfamethoxazole-trimethoprim. His laboratory test results on this day revealed a creatinine level of $1.8 \mathrm{mg} / \mathrm{dL}$, dis-

1. Nephrology Department - Sao Paulo University Medical School - São Paulo, SP/Brazil

2. Division of Pathology - Sao Paulo University Medical School- São Paulo, SP/Brazil

3. Hospital das Clinicas School of Medicine- São Paulo, SP/Brazil Email: silviatitan@superig.com.br crete anemia, hematuria, and nephrotic-range proteinuria (Table 1). Creatinine and urinalysis 3 months before were normal.

Table 1 - Results of laboratory tests.

\begin{tabular}{lcc}
\hline & One week before & On admission \\
\hline Urea (mg/dL) & 89 & 91 \\
Creatinine (mg/dL) & 1.8 & 3.2 \\
Sodium (mEq/L) & & 141 \\
Potassium (mEq/L) & 4.7 & 6.8 \\
Hemoglobin (g/dL) / Hematocrit (\%) & $10.6 / 32$ & $10.2 / 32$ \\
White cell count (per mm mm $^{3}$ & 4860 & 4250 \\
Platelet count (per mm $\left.{ }^{3}\right)$ & 225000 & 207000 \\
Lactate dehydrogenase (U/L) & 922 & 927 \\
Albumin / Globulins (mg/dL) & & $2.2 / 3.1$ \\
Glucose (mg/dL) & & 94 \\
Urinalysis & 2 & \\
Leukocytes (per field) & 10 & 12 \\
Erythrocytes (per field) & $>1$ & $>1$ \\
Protein (g/L) & & 4.52 \\
24h-proteinuria g/day & & 114 \\
Erythrocyte sedimentation rate (mm) & & 2.42 \\
C reactive protein (mcg/mL) & & 24 \\
C4 (mg/dL) & & 103 \\
C3 (mg/dL) & & \\
\hline
\end{tabular}

Normal reference range: lactate dehydrogenase, 240-480 U/L; CRP, $<5 \mathrm{mcg} / \mathrm{mL} ; \mathrm{C} 3,90-180 \mathrm{mg} / \mathrm{dL} ; \mathrm{C} 4,10-40 \mathrm{mg} / \mathrm{dL}$.

On the day he was first seen in our clinic, physical examination revealed a healthy appearance, a blood pressure of $120 \times 70 \mathrm{~mm} \mathrm{Hg}$, normal temperature, pulse of 66 beats per minute, and no signs of edema. Chest, heart, and abdominal examination showed no abnormalities. Cough and fever had vanished, and the patient was feeling well. His new laboratory results demonstrated a rapid worsening in renal function, with a creatinine value of $3.2 \mathrm{mg} / \mathrm{dL}$ (an interval of 1 week after the first test results, Table 1). The 24-hour urine collection confirmed a nephrotic range proteinuria of $4.5 \mathrm{~g} /$ day. Serum albumin was $2.2 \mathrm{mg} / \mathrm{dL}$; total cholesterol was $192 \mathrm{mg} / \mathrm{dL}$; LDL-cholesterol, $52 \mathrm{mg} / \mathrm{dL}$; HDL-cholesterol, $78 \mathrm{mg} / \mathrm{dL}$; and triglycerides, $309 \mathrm{mg} / \mathrm{dL}$. A discrete anemia was noticed, with a normal mean corpuscular volume, serum iron concentration of $90 \mu \mathrm{g} / \mathrm{dL}$, and ferritin of $1882 \mu \mathrm{g} / \mathrm{dL}$. Despite a high LDH, not confirmed 
subsequently, there was no other laboratory evidence of thrombotic microangiopathy, since there was no sign of schistocytes in the blood smear and the haptoglobin level was normal. Hepatitis B serology revealed positive anti-Hbe and total antiHbc antibodies, with negative results for AgHbs, AgHbe, anti-Hbs, and IgM anti-Hbc. Hepatitis C serology and tests for antinuclear and anti-neutrophil cytoplasm antibodies were negative, and the complement levels were normal.

He was admitted in the nephrology ward and underwent a kidney biopsy.

\section{Kidney biopsy}

Light microscopic analysis of a specimen containing 5 glomeruli showed mesangial hypercellularity, an epithelial crescent in 1 glomerulus, tubular focal atrophy with thickening and shrinking of the tubular basal membrane, and fibrosis on $40 \%$ of the interstitial space. Immunofluorescence demonstrated granular deposits of $\operatorname{IgM}$ and $\mathrm{C} 3$ in the mesangium. Electron microscopy revealed expansion of the mensagial matrix, hypertrophy and cytoplasmatic vacuolization of mensagial cells, thickening and segmental splitting of the basal membrane, and hypertrophy and vacualization of podocytes, with diffuse fusion of podocyte foot processes. Electron-dense deposits were noted on the mesangium and subendothelial spaces, and abundant tubuloreticular inclusions were present in the cytoplasm of endothelial cells. Immunohistochemistry for hepatitis B was negative.

Diagnosis: HIV-associated immune complex-mediated glomerulonephritis with a membranoproliferative pattern.

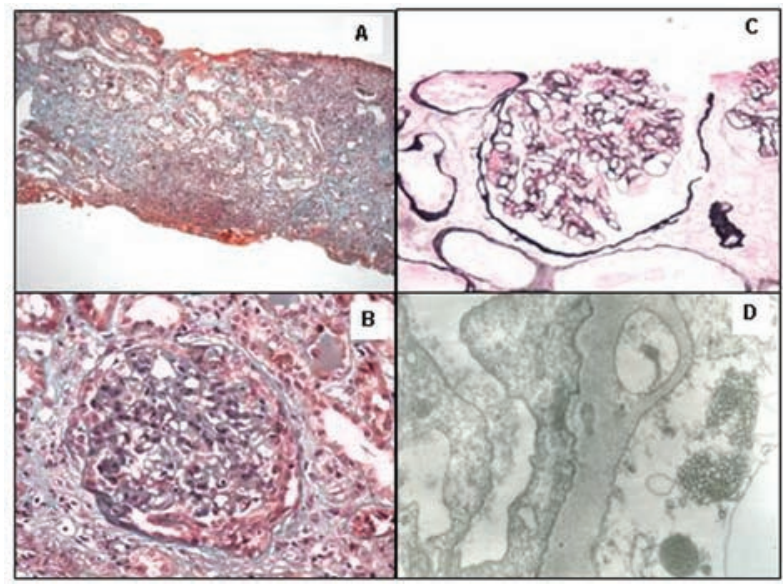

Figure 1 - Kidney biopsy: Panel A shows extensive fibrosis, appearing in trichrome stain $(1,25 \times)$ as green areas. Panel B (Masson stain - 400x) shows global hipercelularity, mostly of mesangial cells and a cellular crescent formation on the right side (arrow). Panel C shows a silver stain exhibiting occasional double contours of the glomerular basement membrane (arrox 400x). Panel D reveals a high power electron micrograph abundant tubuloreticular inclusions in the cytoplasm of glomerular endothelial cells.

\section{DISCUSSION}

Among HIV-associated kidney diseases, HIV-FSGS seems to be the most common form of HIV glomerulopathy. In the United States, this disease is increasing in prevalence, and there is a higher risk among patients of the black race. Recent reports suggest that the same pattern is not observed in various European countries, with a higher proportion of cases attributed to HIV-HUS and immune-mediated glomerulonephritis. ${ }^{3,4}$ Although there is lack of epidemiological data concerning other parts of the world, the incidence of HIV-FSGS in African descendents outside the US does not seem to be so high. ${ }^{5}$

HIV-associated nephropathy can occur in any phase of the HIV infection, including acute seroconversion, but is usually seen later in the disease, when viral load is higher The clinical picture is that of massive nephrotic syndrome, although edema and hypertension are generally absent. Patients can also present non-nephrotic range proteinuria associated with a variable loss of kidney function. Kidney biopsy usually shows a severe form of FSGS, frequently with characteristics of the collapsing form (severe shrinking of the glomerulus accompanied by microcystic tubular dilation). Tubuloreticular inclusions are universally seen, usually located in the cytoplasm of endothelial cells. HIVassociated focal and segmental glomerulosclerosis carries a poor prognosis and is currently the leading cause of endstage renal disease due to HIV in US. ${ }^{6}$ Treatment is based on viral load control involving highly active antiretroviral therapy (HAART) associated with use of angiotesin-converting enzyme (ACE) inhibitors. The beneficial impact of ACE inhibitors in HIV-FSGS was shown in 2 nonrandomized case-control studies, ${ }^{7,8}$ showing reduction of proteinuria and improvement in renal function. More controversial is the use of corticosteroids, with lack of evidence-based data. Although there are reports of improvement of proteinuria and renal function with corticosteroids, a high recurrence rate of nephrotic syndrome and an increase in infectious-associated morbidity and mortality are still a concern.

HIV has become an important cause of HUS-TTP worldwide. The clinical picture is that of typical hemolytyc anemia associated with low platelet count and an increase in biomarkers of hemolysis (LHD, indirect bilirrubin, low haptoglobin). A discrete consuming of complement might be seen as a result of microangiopathy. The renal manifestation is variable, and the disease can present as an acute glomerulonephritis with sudden loss of kidney function, or as a more indolent nephropathy, characterized mainly by non-nephrotic proteinuria and mild-to-moderate renal insufficiency. The kidney pathology is no different from other 
forms of renal microangiopathy: platelet and fibrin thrombi in capillaries and renal arterioles, intimal lesion, fibrinoid necrosis, and mesangiolysis due to ischemia of the glomerulus are all histological features. Typical "onion skin" lesions of microangiopathy might be seen. Immunofluorescence is usually positive for fibrin and fibrinogen, but low positivity for complement fractions and IgM might be present. Tubuloreticular inclusions are also seen, mainly in vascular endothelial cells.

Previously thought to be extremely rare, diverse forms of HIV-associated immune complex glomerulonephritis have recently been described more frequently. Typical postinfectious acute glomerulonephritis, membranous glomerulonephritis, membranoproliferative glomerulonephritis, lupus-like glomerulonephritis, IgA nephropathy, and fibrillary glomerulonephritis ${ }^{3,4,9-11}$ have all been described. Of those, membranoproliferative glomerulonephritis and lupus-like nephritis seem to be the most common forms.

It is possible that the variability in renal histology patterns observed is a result of the interaction between host environmental and genetic factors and a broad spectrum of immunogenicity triggered by the virus. The pathophysiological mechanisms underlying the renal insult remain largely unknown. Direct cytopathic effect, expression of intracellular antigens and deposition of in situ immune complexes, abnormal activation of the immune system with formation of circulating immune complexes, and subsequent renal deposition are all possible explanations. ${ }^{12}$

In this present case, renal pathology showed an acute glomerulonephritis, with signs of splitting of the basement membrane and the appearance of double contours. This histological pattern associated with the presence of tubuloreticular inclusions suggests the diagnosis of HIVassociated immune complex glomerulonephritis. Tubuloreticular inclusions have been described in all forms of HIV-nephritis, from HIVAN, to HUS and immune complex glomerulonephritis. In fact, these inclusions have been described in many organs affected by HIV, and their appearance seems to have a correlation with viral load and disease progression. Despite the initial assumption that these inclusions were composed of viral particles, later studies $^{13-14}$ suggest that they are related to interferon production. Tubuloreticular inclusions (TRI) are not pathognomonic of HIV, although they appear very frequently in this disease: autoimmune diseases ( $\mathrm{SLE}^{15}$, dermatomyositis), lymphoproliferative disease, certain solid tumors, and other viral diseases (parvovirus, Epstein-Barr) have also been associated with these inclusions, suggesting that TRI are probably an immunological epiphenomenon of several diseases.

This case illustrates very nicely how broad the differential diagnosis of HIV-related nephritis can be. This patient was Caucasian, had a CD4 count of 374, and no history of opportunistic infections or drug exposure, and he developed a severe and aggressive form of acute glomerulonephritis. Diagnosis could not be established on clinical and laboratory data, and kidney biopsy was crucial to diagnosis, treatment decision, and prognosis. This case emphasizes that although HIVAN and HUS are the most common forms of HIV-related kidney diseases, we need to consider the immune complex glomerulonephritis as alternative diagnosis.

It might be argued that hepatitis B could be responsible for the acute glomerulonephritis, since the patient has not shown seroconversion to anti-AgHbs. It is known that a few patients with serology showing negative results for AgHbs, AgHbe, and anti-Hbs can have a positive viral load for hepatitis B detected by qualitative assays for detecting serum HBV DNA. More importantly, interpretation of hepatitis B serology is more complicated in HIV patients, since a fall in CD4 is associated with a risk of hepatitis B replication, while antiviral treatment for HIV might cause a reduction in $\mathrm{HBV}$ viral load. Although we could not perform a polymerase chain reaction (PCR) test for hepatitis $\mathrm{B}$ in this case, immunohistochemistry was negative for hepatitis B, suggesting that hepatitis B virus was not associated with the appearance of the glomerulonephritis in this case.

Our patient was started on HAART associated with ACE inhibitors. Considering the good clinical condition of the patient and absence of previous or current opportunistic infections, we also started oral $1 \mathrm{mg} / \mathrm{kg}$ prednisone for 1 month, with full tapering after 3 months. There was a marked improvement in renal function, with a current creatinine of $1.3 \mathrm{mg} / \mathrm{dL}$ (creatinine clearance of $60 \mathrm{~mL} / \mathrm{min}$ ), but no regression of proteinuria ( $4.3 \mathrm{~g} /$ day) after 3 months of treatment. After 1 year of follow-up, creatinine clearance was 73 $\mathrm{mL} / \mathrm{min}$ and proteinuria was reduced to $1 \mathrm{~g} /$ day.

\section{REFERENCES}

1. Weiner NJ, Goodman JW, Kimmel PL. The HIV-associated renal diseases: current insight into pathogenesis and treatment. Kidney Int. 2003;63:1618-31.
2. D'Agati V, Appel GB. HIV infection and the kidney. J Am Soc Nephrol. 1997;8:138-52. 
3. Nochy D, Glotz D, Dosquet P, Pruna A, Guettier C, Weiss L, et al. Renal disease associated with HIV infection: a multicentric study of 60 patients from Paris hospitals. Nephrol Dial Transplant. 1993;8:11-9.

4. Casanova S, Mazzucco G, Barbiano di Belgiojoso G, Motta M, Boldorini $\mathrm{R}$, Genderini A, et al. Pattern of glomerular involvement in human immunodeficiency virus-infected patients: an Italian study. Am J Kidney Dis. $1995 ; 26: 446-53$.

5. Bechar DM, Shlush LI, Maor C, Lorber M, Skorecki K. Absence of HIV-associated nephropathy in Ethiopians. Am J Kidney Dis. 2006;47: 88-94.

6. US Renal Data System (USRDS): USRDS 2001 Annual Data Report. Bethesda MD, The National Institute of Health, National Institute of Diabetes and Digestive and Kidney Diseases, 2001.

7. Burns GC, Paul SK, Toth IR, Sivak SL. Effect of angiotensin-converting enzyme inhibition in HIV-associated nephropathy. J Am Soc Nephrol. 1997;8:1140-6.

8. Kimmel PL, Mishkin GJ, Umana WO. Captopril and renal survival in patients with human immunodeficiency virus nephropathy. Am J Kidney Dis. 1996;28:202-8

9. Haas M, Kaul S, Eustace JA. HIV-associated immune complex glomerulonephritis with "lupus-like" features: a clinicopathologic study of 14 cases. Kidney Int. 2005;67:1381-90.
10. Enriquez R, Cabezuelo JB, Escolano C, Perez M, Amoros F, GutierrezRodero F, et al. Postinfectious diffuse proliferative glomerulonephritis and acute renal failure in an HIV patient. Clin Nephrol. 2004;61:27881 .

11. Cheng JT, Anderson HL Jr, Markowitz GS, Appel GB, Pogue VA, D'Agati VD. Hepatitis C virus-associated glomerular disease in patients with human immunodeficiency virus coinfection. J Am Soc Nephrol. 1999;10:1566-74.

12. Ross MJ, Klotman PE. Recent progress in HIV-associated nephropathy. J Am Soc Nephrol. 2002;13:2997-3004.

13. Luu JY, Bockus D, Remington F, Bean MA, Hammar SP. Tubuloreticular structures and cylindrical confronting cisternae: a review. Hum Pathol. 1989;20:617-27.

14. Orenstein JM, Preble OT, Kind P, Schulof R. The relationship of serum alpha-interferon and ultrastructural markers in HIV-seropositive individuals. Ultrastruct Pathol. 1987;11:673-9.

15. Grausz H, Earley LE, Stephens BG, Lee JC, Hopper J Jr. Diagnostic import of virus-like particles in the glomerular endothelium of patients with systemic lupus erythematosus. N Engl J Med. 1970;283:506-11. 